\title{
SOCIAL WORK LEADER' AUTHENTICITY POSITIVELY INFLUENCES THEIR DISPOSITIONS TOWARD ETHICAL DECISION-MAKING
}

\author{
Radek Trnka ${ }^{1,2}$, Martin Kuška ${ }^{1,2}$, Peter Tavel ${ }^{2}$, Aleš A. Kuběna ${ }^{3}$ \\ ${ }^{1}$ Prague College of Psychosocial Studies, Milanska 471, 10900 Prague 10, Czech Republic \\ ${ }^{2}$ OUSHI, Palacky University, Vodarni 6, 77180 Olomouc, Czech Republic \\ ${ }^{3}$ Institute of Information Theory and Automation of the Czech Academy of Sciences, Pod \\ Vodarenskou vezi 4, 18208 Prague 8, Czech Republic
}

\begin{abstract}
The personality traits of social work leaders are important factors influencing ethical decision-making in organisations. The lack of empirical evidence with regard to the relationship between personal authenticity and ethical decision-making in social work stimulated the present study. Two hundred thirty-eight leaders ( $81.9 \%$ female) from organisations working in various fields of social work were administrated with the Authenticity Scale, Managerial Ethical Profile, and conducted two free association tasks with the cue words authenticity and self. Authenticity was positively correlated with ethical decision-making. In contrast, authenticity was not correlated with the tendency to make decisions in an effort to maximise economic profit for the organisation. The results of the present study have important practical implications for the social work sector. The positive correlation of authenticity with ethical decision-making indicates that positive reinforcement of authenticity in leaders could possibly lead to supporting ethical decision-making within an organisation. Therefore, supporting authenticity in leaders working in social work may also help foster quality services and prevent unethical behaviour.
\end{abstract}

This is the accepted version of the manuscript, the Version of Record of this manuscript has been published and is available in European Journal of Social Work, 2019,

https://www.tandfonline.com/10.1080/13691457.2019.1608513

Keywords: social work; social services; social services organisations; ethics; ethical decisionmaking; ethical issues; ethical dilemmas; ethical behavior; unethical behavior; unethical decisions; immoral practices; situational ethics; moral policy; leader; leadership; manager; managerial; health services; counseling; human characteristics; personality; authenticity; metaethics

MeSH Headings: Social Work; Leadership; Decision Making; Community Health Services; Counseling; Counselling

\section{Introduction}

Ethical behaviour and ethical decision-making (EDM) are very desirable in leaders in the sphere of social work and caring professions (Evans \& Hardy, 2017). Decision-making in social work is generally expected to be strongly guided by ethical principles, such as social justice (Staub-Bernasconi, 2017; Urek, 2017), reciprocity (Kjorstad, 2017), toleration (Besch \& Lee, 2018), responsibility (Hyslop, 2018) or respect (Gupta \& Blumhardt, 2018; Yeung, Ho, Lo, \& Chan, 2009). Also, du Preez and Goedeke (2013) highlighted the importance of development of an EDM model for caring professions and counselling. In addition to other factors, leaders' personal dispositions, such as personality traits, values and attitudes, are 
considered to be key sources for successful implementation of ethical principles into decisionmaking in social work.

\section{The complexity of EDM in social work}

Social work leaders as well as practitioners face a number of ethical dilemmas in their everyday decision-making. The appropriate solving of these dilemmas helps in making decisions that mediate a client's access to care, influences the quality of care or improves the client's own decision-making efforts (Proctor, 2002). EDM pervades an organisation, among employees as well as the service users. When analysing the consequences of EDM, one should take into account both the advantages and disadvantages of EDM for multiple constituencies. Social work leaders may benefit from EDM, because decisions based on solid ethical grounds enhance both their professional and personal competency and also contribute to a positive public image of the profession (Lawler, 2007). On the other hand, the professional community and the wider society have demanding expectations relating to EDM in social work organisations (Clark, 2011). These expectations, together with the complexity of the ethical dilemmas, may lead to stress in social work professionals (Clark, 2011; Ulrich et al., 2010) as well as to severe consequences, such as losing a job in the cases of unethical decisions or immoral practices (Hedin \& Månsson, 2012). Thus, an implicit requirement of EDM boosted by external as well as internal expectations may also be related to the psychic load and stress at the workplace within social work organisations.

EDM is often difficult and complex in social work practice (Freud \& Krug, 2002; Osmo \& Landau, 2006). Several problems may occur during the implementation of EDM in social work organisations. For example, the effectiveness of EDM may be negatively influenced by an emphasis on simplification, routinisation and the quest for a single truth (Clark, 2011; Hansen, 2012). The social work profession may be simplified and technicalised by various checklists, prescribed manuals, rulebooks and rigid problem-solving algorithms. Such overstructured, rule-based decision-making may fail in cases that require the solving of highly complex ethical dilemmas. In contrast to the reductive approach to ethics, Jungers and Gregoire (2016) recommended stimulating authenticity in social work leaders. Supporting authenticity in leaders is suggested to help them reorientate their reflections on how to become ethical, personally invested professionals, to acknowledge fully the variety of possibilities at hand for resolving an ethical issue and to follow the mission of the profession upon which its moral framework rests (Jungers \& Gregoire, 2016).

\section{Authenticity in social work}

Authenticity plays an important role when considering ethical and responsible leadership (Freeman \& Auster, 2011; Brown \& Treviño, 2006; May, Chan, Hodges, \& Avolio, 2003), and previous research has brought evidence that highly authentic leaders had a lower propensity to morally disengage and a lower tendency to behave unethically (Knoll, Lord, Petersen, \& Weigelt, 2016). Despite some theoretical papers highlighting the important role of authenticity in the caring professions (Floyd \& Rhodes, 2011), only a few empirical studies have dealt with authenticity in leaders within the social work sector. Nurses from different specialties underwent simulation-based training focused on the development of authentic leadership abilities (Shapira-Lishchinsky, 2014). They benefited from the training by increased self-awareness of their strengths and weaknesses, greater responsibility in decisionmaking and an increased willingness to analyse and explore other opinions. The impact of perceived authenticity of organisational behaviours was recently investigated among full-time employees in medium- and large-sized companies in the U.S., including organisations of helping professions and social work (Lee \& Kim, 2017). This research was not specifically focused on social work, but the results showed that an organisation's authentic behaviours 
related positively to perceived communal relationship. The authors also pointed out that the authentic behaviour of whole organisations was related to trustfulness, transparency and consistency. Furthermore, women who participated in a preparation-for-mentoring program focused on helping socioeconomically disadvantaged communities were investigated in the study of Boddy, Agllias, and Gray (2012). Authenticity was considered here to be one of most important personal dispositions for building a successful community-based mentoring relationship.

\section{Humanistic approach to authenticity}

In psychology, the humanistic approach to authenticity inspired by the Rogers' theory of personality has recently been followed by many scholars (for an overview, see Joseph, 2017). This theory includes three main components: a) lack of self-alienation involving a consistent sense of identity, which is in accordance with person's primary experience or 'true self' (i.e. physiological states, emotions, inherent tendencies and beliefs), b) authenticity occurs when one's behaviour is in accordance with their beliefs and values, i.e. when one's behaviour reflects the individual's conscious awareness of their 'true self', c) not accepting external influence, when it goes against personal beliefs (Lenton, Slabu, \& Sedikides, 2016; Maltby, Wood, Day, \& Pinto, 2012; Wood, Linley, Maltby, Baliousis, \& Joseph, 2008). Furthermore, the true self is suggested to be an important source of existential meaning, and people use their true selves as a guide for a variety of decisions in order to imbue those decisions with meaning and value (Schlegel, Vess, \& Arndt, 2012). Within the counselling professions, "being authentic means forging a professional self that is fully conscious, informed by the profession's mission, and freely able to engage one's own and the profession's possibilities for growth and development." (p. 109, Jungers and Gregoire, 2016).

\section{Model of authentic ethical leadership behaviour}

Zhu, May, and Avolio (2004) developed a theoretical model of authentic ethical leadership behaviour (Figure 1). Authentic behaviour represents a behaviour which is consistent with the leader's deontology, ethical values and moral intentions, which are also transparently expressed toward their employees. High personal authenticity of leaders, also including consistency between moral intentions and behaviours, is a key feature increasing trust in employees toward leaders (Zhu et al., 2004). This theoretical model proposes a positive relationship between authenticity and ethical behaviour. EDM is one of the types of ethical behaviour, i.e. the way a leader's deontology, ethical values and moral intentions may be expressed. Furthermore, Knoll et al. (2016) found that highly authentic leaders had a lower tendency to behave unethically. Therefore, for the purpose of the present study, we hypothesise that highly authentic leaders are more disposed to make EDM.

\section{Model of EDM}

When seeking a specific model for EDM, the theory of multidimensional EDM (Casali, 2011; Casali \& Day, 2015) provides us with an interesting theoretical background. This theory understands EDM to be composed of eight closely interrelated dimensions: economic egoism, reputational egoism, act utilitarianism, rule utilitarianism, virtue of self, virtue of others, act deontology, and rule deontology. These individual characteristics are suggested to influence ethical judgments and decision-making, i.e. a leader's EDM style. The above-outlined ethical principles postulated by the theory of multidimensional EDM (Casali, 2011) may be related to a leader's expression of his or her authentic self at work. The virtue of the self and the virtue of others represent the virtue ethics dimension. In particular, the virtue of self denotes 
decision-making influenced mostly by one's core personal values, in other words, to take decisions that are in accordance with one's true self. In contrast, the virtue of others denotes much more some kind of contextual morality. Such decision-making is influenced by caring for others and the ethics of care and responsibility toward others. Reputational egoism, i.e. protecting the reputation of the organisation, represents another possible motivation for decision-making. Rule deontology and rule utilitarianism denote fulfilling universal duties, or acting according to universal principles like justice, not harming others, doing good or respecting autonomy (Casali, 2007, 2011). Act deontology and act utilitarianism refer to giving the opportunity to all affected parties to participate in decision-making. Finally, economic egoism is conceptualised as a personal disposition to make decisions in an effort to provide the highest economic profit for the organisation, to minimise costs for the organisation, to optimise resources of the organisation and to attain the organisational annual budget.

\section{Present study}

Given the lack of empirical evidence focused on the relationship between authenticity and EDM in the social work sector, the present study aims to contribute to the current state of knowledge in this area. We examined the relationship between the trait authenticity and the disposition to EDM in leaders from social service organisations. An additional task of the present study was the exploration of participants' internal concepts of authenticity. Subjective meanings relating to authenticity and the true self are derived from conceptual knowledge stored in one's memory (e.g. Smith \& Medin, 1981). Internal concepts may be recalled and expressed through language. Therefore, the additional goal was to reveal what kinds of authenticity-related associations occur when participants are primed with the cue word authenticity in a free association task (Nelson, McEvoy, \& Schreiber, 2004). Additionally, self-related associations were explored to verify the interconnection between participants' internal concepts of the self and authenticity.

\section{Method \\ Participants}

Two hundred thirty-eight individuals (mean age $=38.15, \mathrm{SD}=10.73 ; 81.9 \%$ female) were recruited from organisations working in various fields of social work in the Czech Republic. All participants had leading positions within their organisations. The participants were contacted by e-mail or phone. The questionnaires were later administered during a personal encounter. The leaders from 116 organisations were included in the sample; $17 \%$ of them worked in small organisations of up to 20 employees, $60 \%$ worked in medium-size organisations of 21-500 employees and 23\% worked in bigger organisations of 501-10,000 employees. In all, $64 \%$ of the leaders were at the lower levels of management, and $36 \%$ were at the middle or higher levels of management. Leaders from both governmental and nongovernmental social services organisations were included in the sample. The aim was to include social services organisations of different types, e.g. focused on different target groups. Therefore, the sample covered social services organisations focused on care for children, seniors, the unemployed, refugees, addicts and physically disabled as well as mentally disabled individuals (see Figure 2 for the proportions according to organisation type). 


\section{Procedure}

The participants first filled in their basic demographic characteristics. Subsequently, they were administrated with the Authenticity Scale (AS, Wood et al., 2008), two free association tasks (Nelson et al., 2004) and finally with the Managerial Ethical Profile scale (MEP scale, Casali, 2011). The time for completing the scales and the free association tasks was not limited.

The research design was approved by the institutional ethics committee in line with the approving college's policies and procedures. All participants signed an informed written consent with their participation in the study.

\section{Measures}

\section{Authenticity Scale}

The AS (Wood et al., 2008) was used to measure the trait authenticity. It consists of 12 items rated on a scale where $1=$ strongly disagree and $7=$ strongly agree. The AS includes three subscales: Authentic Living (items like 'I live in accordance with my values and beliefs'), Self-Alienation (items like 'I feel as if I don't know myself very well') and Accepting External Influence (items like 'Other people influence me greatly').

Free association task

The free association task (Nelson et al., 2004) with multiple associations to the cue words was used in the present study. The main aim was to explore the conceptual categories that participants retrieve when they are asked to recall associations to the word authenticity and the word self. The participants were asked to recall five words relating with the cue word with the instruction 'Please, write 5 words that you recall when you hear the word authenticity to the following 5 lines'. Five short horizontal lines placed below each other were offered to respondents below the instruction. Afterwards respondents were asked to recall five words relating to the cue word self with the same instruction and response design.

Managerial Ethical Profile

The Managerial Ethical Profile scale (MEP scale, Casali, 2011) was used to capture the disposition to EDM. The ethical factors are represented by 24 items that are originally subdivided into eight subscales: Economic Egoism (items like 'Providing the highest economic profit for the organisation'), Reputational Egoism (items like 'Protecting the reputation of the organisation'), Rule Utilitarianism (items like 'Obeying the law'), Act Utilitarianism (items like 'Creating the greatest overall benefit for the local community'), Virtue of Self (items like 'Being most in line with your core personal values'), Virtue of Others (items like 'Respecting the dignity of those affected by the decision'), Act Deontology (items like 'Giving the opportunity to all affected parties or their representatives to have input into the decision-making process'), and Rule Deontology (items like 'Maintaining a fair process at all times'). The answers were of the five-point Likert scale type, ranging from 1 (not important al all) to 5 (extremely important).

\section{Results \\ Data preparation and analysis notes}

The associations acquired from the free association task were analysed separately for each cue word, i.e. authenticity and self. The data were categorised according to the meaning of each association. The categories of associations were created based on semantic similarity of associations, i.e. associations with similar semantic meaning were grouped in a separate category. Two separate categorisation systems were developed for the associations of both cue words, authenticity and self (see below). The fit of the associations into the categories were examined by an independent assessor. An independent rating showed $86 \%$ congruence 
in the ex-post classification of the associations, namely $88.1 \%$ congruence for authenticityrelated associations and $83.8 \%$ congruence for self-related associations.

When considering the psychometric properties of the used scales, the AS showed a total Cronbach's $\alpha=.74$, with the subscales' Cronbach's Accepting External Influence $\alpha=.77$, Self-Alienation $\alpha=.76$, and Authentic Living $\alpha=.69$. The MEP scale showed overall a Cronbach's $\alpha=.86$. The Principal Component Analysis (PCA) did not confirm the eight original subscales of the MEP scale. This analysis showed that two of the components had eigenvalues higher than two, which means that PCA fits well with the data and is a suitable method for explaining the factor structure of the MEP scale. From the others, only four (not six) components were confirmed, and one of them was close to one $\left(\lambda_{6}=1.001\right)$. In other words, these results mean that instead of the eight original subscales of the MEP scale, PCA revealed that only two components, Ethical Factor of Decision-Making and Economic Egoism, were appropriate for further analysis. The second component $\left(\lambda_{2}=2.834\right)$ was mostly saturated by sub-items from the Economic Egoism scale (see Figure 3). In particular, a leader's disposition to make decisions in an effort to maximise economic profit for the organisation, minimise costs for the organisation, optimise resources and attain an organisational annual budget are examples of subitems that saturated the Economic Egoism scale. The remaining subitems relied $\lambda_{2}=6.547$. At the same time, all items except the subitems from the Economic Egoism subscale showed significantly higher reliability (Cronbach's $\alpha=.87$ ) than the original subscales (Cronbach's alphas ranging from .49 to .78). For these reasons, a two-factor solution of the MEP scale was considered more appropriate for further analyses, i.e. to consider the Ethical Factor component of Decision-Making (Cronbach's $\alpha=$ .87 ) and the Economic Egoism component (Cronbach's $\alpha=.78$ ).

\section{Relationship between authenticity and EDM}

Kendall's correlations were used for the examination of the relationship between the AS and the MEP scales. Kendall's $\tau$ was chosen from all correlational coefficients, because of the possibility of direct and easy interpretation of value of Kendall's $\tau$. More specifically, $(1+$ $\tau) / 2$ is the probability that from two randomly selected participants, a more authentic participant will be also more disposed to make ethical decisions. Furthermore, we also consider the fact that the Shapiro-Wilk's test disproved the normality of some variables, i.e. Accepting External Influence $(p=.009)$, Self-Alienation $(p<.00)$ and the Ethical Factor of Decision-Making $(p=.004)$. This means that the variables are only slightly different from normal distribution. When normal distribution is achieved, the results will be nearly the same.

When testing overall correlations between the scales, the AS was positively correlated with the MEP scale (Kendall's $\tau_{b}=.092, p=.005$ ). More authentic participants were more disposed towards EDM. When testing the correlations on the level of subscales, the Ethical Factor of Decision-Making was negatively correlated with Self-Alienation (Kendall's $\tau_{b}=-$ $.138, p=.002$ ) and independently of this, positively correlated with Authentic Living (Kendall's $\tau_{b}=.104, p=.021$ ). The participants with higher levels of Authentic Living also had higher dispositions to make ethical decisions. This fits well with the other finding, because Self-Alienation has inverted influence within the conceptualisation of the AS. Thus, participants with higher levels of Self-Alienation were less disposed towards EDM. Economic Egoism was not correlated with any of the AS subscales.

\section{The occurrence of associations related to authenticity and self}

Eight different categories emerged in the participants' authenticity-related associations from the free association task (Figure 4). $69 \%$ of the participants reported at least one association pertaining to the category Personal Trait (associations like credibility, openness, objectivity; $N$ 
$=165), 59 \%$ of the participants reported at least one association pertaining to the category True Self (associations like genuineness, primary source, essence; $N=140$ ), and $42 \%$ of the participants reported at least one association pertaining to the category Value (associations like truth, freedom, honour; $N=99$ ). The remaining categories showed occurrences lower than $30 \%$, specifically:

- 29\% Individual (associations like me, myself, individuality; $N=68$ )

- $25 \%$ Uniqueness (associations like uniqueness, originality, extraordinariness; $N=$ 59)

- $20 \%$ Emotion (associations like emotion, feeling, affects, $N=48$ )

- $19 \%$ Presence (associations like presence, actuality, here and now, $N=45$ )

- $15 \%$ People (associations like people, clients, social environment, $N=35$ )

Nine different categories emerged in the participants' self-related associations from the free association task (Figure 5). The participants most often associated self with the category Individual (associations like me, my, ego, my name), more specifically, 69\% of the participants reported at least one association pertaining to this category $(N=165)$. Three categories had occurrences higher than $35 \%$, specifically:

- $39 \%$ Personal Trait (associations like self-confidence, patience, consideration; $N=92$ ),

- $37 \%$ Social Role (associations like mother, sister, husband; $N=88$ )

- $36 \%$ Emotion (associations like love, self-love, joy; $N=86$ ).

The remaining categories showed occurrences lower than 33\%, specifically:

- $32 \%$ People (associations like community, society, others; $N=77$ )

- $29 \%$ Value (associations like truth, freedom, honour; $N=70$ )

- 20\% Physicality (associations like brain, head, blood; $N=47$ )

- $18 \%$ Work (associations like work, I work, key worker; $N=43$ )

- $13 \%$ Leisure (associations like dance, yoga, horse-riding; $N=30$ )

The relationship between the occurrences of authenticity-related associations and selfrelated associations was tested using the Mantel Test. The occurrences of authenticity-related associations and self-related associations were significantly correlated $(r=.067, p=.0015)$ when testing the occurrence/non-occurrence of associations using Hamming's distance between subjects, which shows increased probability when both kinds of associations occur simultaneously. Patterns in the recall of words relating to authenticity were significantly correlated to patterns in the recall of words relating to self, and vice versa.

\section{Relationship between authenticity and authenticity-related and self-related associations}

The relationship between authenticity measured by the AS and authenticity-related associations was tested by the Decision Tree CHAID classification technique (Figure 6). The occurrence of associations pertaining to the category Value was significantly related to the subscale Authentic Living (adjusted $p=.033$ ). Participants reporting higher Authentic Living were less disposed to report an association pertaining to the category Value $\left(\eta^{2}=.019\right)$ than participants lower in Authentic Living. The occurrence of associations pertaining to the category People was significantly related to the subscale Accepting External Influence (adjusted $p=.036$ ). Participants reporting higher Accepting External Influence were more prone to report an association pertaining to the category People $\left(\eta^{2}=.019\right)$. No significant relationship was found between the occurrence of authenticity-related associations and the subscale Self-alienation.

The relationship between authenticity and self-related associations was also tested using the Decision Tree CHAID classification technique (Figure 7). The occurrence of associations pertaining to the category Social Role was significantly related to the subscale Authentic 
Living (adjusted $p=.028$ ). Participants reporting higher Authentic Living were less prone to report associations pertaining to the category Social Role $\left(\eta^{2}=.021\right)$, and the occurrence of associations pertaining to the category Physicality was significantly related to the subscale Self-alienation (adjusted $p=.018$ ). Participants reporting higher Self-alienation were more prone to report associations pertaining to the category Physicality $\left(\eta^{2}=.032\right)$.

For the subscale Accepting External Influence, the structure of the decision tree was more complex (see Figure 7). The occurrence of associations pertaining to the category Leisure was the most significant factor relating to the subscale Accepting External Influence (adjusted $p=$ .011). Participants reporting higher Accepting External Influence were more prone to report associations pertaining to the category Leisure $\left(\eta^{2}=.031\right)$. In the $87 \%$ of participants $(N=$ 205) who did not report associations pertaining to the category Leisure, the occurrence of associations pertaining to the category Value was significantly related to the subscale Accepting External Influence as a further differential factor (adjusted $p=.017$ ). In the $61 \%$ of participants $(N=143)$ who did not report associations pertaining to the category Leisure neither associations pertaining to the category Value nor the occurrence of associations pertaining to the category Personal Trait was significantly related to the subscale Accepting External Influence as a further differential factor (adjusted $p=.20$ ).

\section{Age and gender differences}

Age differences in the AS and MEP scale were tested with Kendall's correlations. Age was negatively correlated with the Ethical Factor of Decision-Making (Kendall's $\tau_{b}=-.119, p=$ .009). Younger participants were more disposed to EDM than older participants. No age differences were found in the AS. Gender differences in the AS and MEP scale were tested by the Hotelling test, with no significant gender differences being found $(p=.165)$.

\section{Discussion}

Values and ethics belong among the key elements of social work leadership (Lawler, 2007). This implies that decision-making by social work leaders proceeds with respect to a professional code of ethics, human dignity and concern for human service (Bisman, 2004). The results of the present study showed that personal authenticity was positively correlated with EDM in leaders working in the various spheres of social work. In other words, social work leaders with high levels of trait authenticity were more disposed to employ EDM. This finding was also supported by considering the specific facets of authenticity. The Ethical Factor of Decision-Making was negatively correlated with self-alienation and positively correlated with the Authentic Living subscale. Social work leaders with a greater sense of authentic living, i.e. who live in accordance with their own true self, were also more disposed to EDM. In contrast, leaders who reported feeling detached from their true self, or in other words, reported feeling that they do not really know themselves, were also less disposed to EDM.

Interestingly, Economic Egoism, the second factor resulting from use of the MEP scale (Figure 3), was not correlated with any of the subscales of the AS. Economic egoism is conceptualised as a leader's disposition to make decisions in effort to maximise economic profit for the organisation, minimise costs for the organisation, optimise resources and attain an organisational annual budget (Casali, 2011). These facets were understood distinctively than all other facets of the MEP scale by the social work leaders included in our sample. These other facets saturating the Ethical Factor of Decision-Making (Figure 3) included various personal dispositions, such as respecting the dignity of people affected by a decision, creating the greatest overall benefit for the community, maintaining a fair process at all times, respecting the organisation's rules, protecting the reputation of the organisation, or not 
harming the clients. In contrast to these facets, significantly correlating with leaders' trait authenticity, motivations to make decisions in effort to provide the highest economic profit for the organisation and minimise costs seem to represent a different kind of personal disposition. These results also resonate with a leadership ideology favouring responsibility for a budget and accountability. The shift to managerialism in social work has been extensively criticised, because importing a business, market-oriented model to the social service sector faces many problems, e.g. the preference for values such as economy, efficiency and accountability over social and moral values (Rogowski, 2011; Tafvelin, Hyvönen, \& Westerberg, 2014). Greater proceduralisation accompanying managerialism also leads to decreased intrinsic motivation of social workers and reduces the autonomy of frontline staff (Kirkpatrick, Ackroyd, \& Walker, 2005; Lawler, 2007). The results of the present study indicate that personal dispositions toward minimising costs for the organisation, optimising resources and meeting an organisational budget were not related to personal authenticity and the Ethical Factor of Decision-Making. In other words, personal dispositions favouring economy, efficiency and accountability seem to be independent of dispositions toward authentic leadership and EDM. The inclusion of Economic Egoism in the general model of EDM (Casali, 2011; Casali \& Day, 2015) is questionable and should be scrutinised in future theory refinements.

Effective leadership in social work is strongly based on the quality of the leader-follower relationship (Elpers \& Westhuis, 2008). When interpreting the results of the present study within the framework of recent theory of authentic ethical leadership behaviour (Zhu et al., 2004), some important implications for the transfer of moral values from the leader to the social work staff should be addressed. The theory suggests that authentic ethical behaviour of leaders increases employees' psychological empowerment, i.e. their commitment and trust in leaders. These interpersonal effects have important implications for transformational leadership that have recently been of growing interest in social work organisations (Lawler, 2007; Mary, 2005; Tafvelin et al., 2014). Transformational leadership is based on the strong identification of employees with a leader and his/her moral values and attitudes (Bass \& Riggio, 2006). A charismatic leader is suggested to be able to influence employees' awareness, moral values and identification with the philosophy of the organisation. In this context, the strong personal authenticity of a leader may be helpful for the effective transfer of moral values from the leader to employees. Authentic leaders performing EDM are suggested to contribute to the transfer of moral values to the social work staff, to inspire loyalty and promote higher intrinsic motivation in employees, and to increase commitment to the social work organisation.

Furthermore, the present study contributes to current knowledge by mapping the structure of authenticity-related associations. The emergence of eight different broader pools of associations showed us different ways of subjective conceptualisation of authenticity in leaders working in the social work sector (Figure 4). Consistently with the recent humanistic theory of authenticity (Lenton et al., 2016; Maltby et al., 2012; Wood et al., 2008), several categories of associations mirrored various facets of the true self. Namely, the categories Individual, Value and Emotion are in accordance with the initial definition of a person's primary experience of 'true self', i.e. physiological states, emotions, inherent tendencies, values and beliefs. The highest amount of associations was classified into the category Personal Trait. This rich category included associations mirroring various personal traits, or in other words, subjective beliefs about one's own personality. The second biggest pool of associations was the category True Self. These associations may be assumed to be core associations, as they include words that can be considered straight labels for the true self, for example, words such as 'primary source' or 'essence'. The frequent occurrences of these associations indicate the ability of participants to label the true self in their own folk terms. 
In contrast, the occurrence of authenticity-related associations denoting people and the social environment were relatively low in comparison to associations mirroring the true self. The associations relating to people and the social environment were the least represented pool of associations in comparison to all other pools of associations mirroring leaders' internal concepts of authenticity, i.e. Individual, True self, Uniqueness, Personal Trait, Value, Emotion, Presence. This finding fits well with the Rogerian theoretical understanding of authenticity. In this perspective, accepting an external influence, including also accepting influences from the social environment, has an opposite influence in relation to trait authenticity in a given person. In other words, less authentic persons are suggested to be more prone to accept external influences. In accordance with this finding, the results of the present study also showed that the occurrence of associations pertaining to the category People was significantly related to the trait authenticity of social work leaders, specifically to the subscale Accepting External Influence. This denotes that less authentic leaders, i.e. leaders more prone to accept external influences, were also more likely to report associations relating to people or the social environment. In contrast, more authentic leaders without a tendency to be strongly influenced by external influences had internal concepts of authenticity that did not consider the influences of the social environment. The results of previous studies (Elpers \& Westhuis, 2008; Gellis, 2001; Mary, 2005) showed that a leader's transformational leadership style with participatory decision-making was associated with employees' organisational performance, commitment and job satisfaction. If participative decision-making is an important factor influencing job satisfaction in social workers, then further consequences of trait authenticity of social work leaders should be discussed. Despite the fact that authentic leaders are more prone to perform EDM in social work, excessive authenticity may be a factor contributing concurrently to a reduction of job satisfaction among the social work staff. Also, Jungers and Gregoire (2016) pointed out that authenticity may strengthen the dichotomy between a person and the community, i.e. between the social work leader and social work staff in our case. Excessive authenticity may even elicit the feeling that the person exists apart from the community. From this viewpoint, a leader encapsulated in his/her own world may even devalue the core principles and standards of social work when making decisions (Jungers \& Gregoire, 2016).

In the case of self-related associations, the occurrence of associations pertaining to the category Social Role was significantly negatively related to the subscale Authentic Living. Leaders with a greater sense of authentic living were less prone to report associations pertaining to the category Social Role. We interpret this finding by the assumption that the self of highly authentic leaders is more independent and less strongly identified with social roles in comparison to less authentic leaders. Highly authentic leaders may show high crosssituational consistency, i.e. consistency across relationships, roles, contexts, including also consistent inner representation of the self (Boucher, 2011). Therefore, dependence of the self on social roles may be suggested to be relatively weak in highly authentic leaders in comparison to less authentic leaders. These results also indicate that highly authentic leaders may be more autonomous during their decision-making. In contrast, excessive dependency on social roles may limit the autonomy and independence of a leader's decision-making.

Autonomy and independence have been found to increase professional confidence and capability in social work (Trowler, 2017).

\section{Practical implications}

The results of the present study have important implications for the sectors of social work and caring professions. The positive correlation of authenticity with EDM indicates that positive reinforcement of authenticity in leaders would possibly lead to supporting EDM within an organisation. Ethical and responsible leadership (Freeman \& Auster, 2011) may foster quality 
of services for social service users and prevent unethical behaviour and unethical decisionmaking. From this perspective, supporting authenticity in leaders is very desirable. Two general ways may be considered. First, the effort may be focused on selecting leaders with authentic personalities or leaders with suitable personal dispositions for future personality development, leading to authentic and responsible leadership. Second, nurturing and encouraging authenticity by specific training programs can be supported in organisations (Knoll et al., 2016). Liang (2017) suggested that organisations should make high investments in training programs to develop their authentic leadership behaviours, because leaders with high levels of dispositional authenticity can increase employees' perceptions of self-worth and their trust toward leaders.

In practice, several techniques for building authentic leadership dispositions can be found. For example, training programs based on simulation-based learning have been shown to be effective in fostering authentic leadership (Shapira-Lishchinsky, 2014). Such group training sessions start with the exposing of participants to some kind of ethical dilemma. The focus on the participants' own experiences from his/her practice in particular is suggested to effectively facilitate learning transfer. After that, simulation of the chosen ethical dilemma is performed by participants with the use of role-playing. The simulations are videotaped and later discussed and analysed, with the focus on determining the focal points that highlighted the decision-making processes, ethical dilemmas and outcomes. In all kinds of group training procedures, a supportive and non-judgemental atmosphere needs to be created to support effective learning transfer.

The utilisation of mentors is another way of building authentic ethical competence in social work leaders. Social work leaders of high moral courage and resiliency are suggested to be a suitable "models of performance" in mentoring programs focused on authentic leadership development (May et al., 2003). During one-to-one as well as group mentoring sessions, the participants are provided with practical examples of EDM conducted by experienced social work leaders. This approach works on the principle of perspective-taking when participants co-experience solving typical ethical dilemmas during decision-making in a social work organisation. The effective development of authentic leadership springs from building capacities to think about ethical dilemmas in alternative ways and becoming sensitive to the nature of the consequences that leaders' decisions have for the organisation, the employees and the service users.

Furthermore, Shamir and Eilam (2005) pointed out the importance of developing a meaning system from which leaders can act authentically. This approach shifts the focus from the currently widespread emphasis on the development of skills and behavioural styles to an emphasis on development of a leader's self-concept and meaning system. This shift represents an important challenge for future development of innovative training programs within the social work sector. The present study offers further new insights for the issue of a leader's self-concept and meaning system. The free association task was utilised for mapping a leader's self-concept. This technique showed good potential for quick, albeit only brief, assessment of self-concept in leaders. It can be fruitfully utilised in practice, for example, when evaluating candidates for leadership positions, or in training programs focusing on development of self-concept and an authentic meaning system.

\section{Limitations and future directions}

The present study also has some limitations. The research design was focused solely on the leaders' trait authenticity. The observation of actual moral behaviour of leaders instead of considering dispositions for EDM would be beneficial for future explorations of the relationship between authenticity and EDM. Authenticity is also a crucial factor for leadership in general, not only for leaders' EDM (Petkeviciute, Barvydiene, \& Surpikiene, 2018). 
Constructing authenticity at the workplace and building relational authenticity within an organisation are examples showing other dimensions of authentic leadership. Furthermore, the present study did not focus on the trait authenticity in practitioners in the organisations from which the leaders were recruited. Future studies may also consider the links between leaders' authenticity, practitioners' authenticity, practitioners' trust in leaders, or approach authenticity in leader-practitioner dyads.

EDM and practice ethics are suggested to be closely connected with personal values (Clark, 2011; Schwartz, 2016). Therefore, the authenticity of social work leaders is not the sole condition for assuring EDM in social work organisations. Moral character dispositions should be also considered to get a more complex picture about a leader's personality tending to make decisions based on solid ethical ground. Moral maturity, ethical predisposition, integrity capacity, moral sensitivity, moral ownership, moral efficacy and moral courage are examples of personal traits related to EDM (Schwartz, 2016). Furthermore, the recent study of Knoll et al. (2016) proved that moral disengagement would be a possible mediator of the relationship between authenticity and unethical behaviour. Therefore, the possible role of moral disengagement in the relationship between authenticity and ethical-decision making should be explored by future studies.

The social work organisations included in the present study differed in size. It is necessary to say that the impacts of EDM also differ, for example, when considering a big governmental organisation and a small non-governmental organisation. Whereas impacts of decisions made in big governmental organisations are often crucial for large numbers of social service users, the impacts of decisions in small non-governmental organisations are often local or smallscale. Building relational authenticity at the workplace also proceeds differently in big organisations and in small organisations up to 20 employees.

Acknowledgments: Many thanks to Karel Balcar, Hana Hejná, and Karel Hnilica for their kind support and inspiring suggestions during the final stage of manuscript preparation. This work was supported by the Czech Science Agency, project DYME - Dynamical Models in Economics, GAP402/12/G097.

\section{Notes on contributors}

Radek Trnka is a lecturer and senior researcher at the Prague College of Psychosocial Studies and Palacky University Olomouc. His research interests include emotions, personality, creativity, coping, and systemic and quantum approaches in psychology and anthropology. He contributed to the establishment of a new, arising discipline called 'quantum anthropology' that is seeking interconnections between quantum theoretical thinking and contemporary psychology and anthropology. Most of core issues of quantum anthropology were introduced in his recent book 'Quantum anthropology: Man, cultures and groups in a quantum perspective' (2016, Charles University Karolinum Press, available for download without cost here:

https://www.researchgate.net/publication/308792484_Quantum_Anthropology_Man_Cultures_and_G roups_in_a_Quantum_Perspective)

Martin Kuška is a lecturer and senior researcher at the Prague College of Psychosocial Studies, at the departments of psychology and social work. Since 2012, he is also lecturing at the Sigmund Freud Private University Vienna, Psychotherapy Science department. His research focuses on interdisciplinary approaches in psychosocial sciences. Recent publications concern themes such as cultural factors in psychotherapy, emotionality and emotional creativity, ageing, treatment outcomes interpretation, or youth subcultures. He is also cooperating with the Olomouc University Social Health Institute, Palacky University Olomouc.

Peter Tavel is a professor in clinical psychology at Palacky University Olomouc, Czech Republic. His theoretical work and research are focused on the meaning of life, the psychology of ageing and lenitixe 
relief, risk/protective factors in adolescents and the relationship between psychology, spirituality and faith.

Aleš A. Kuběna is a postdoctoral researcher in the field of descriptive and normative game theory at the Institute of Information Theory and Automation, Czech Academy of Sciences, Czech Republic. His expertise is in research of conflicts between ethical and strategic decision-making, truth-mining and analysis of information with a special focus on subjects' motivation to distort the information. From the game-theoretical point of view, he explores the science itself as a majestic collective action.

\section{References}

Bass, B. M., \& Riggio, R. E. (2006) Transformational leadership (2nd ed.). Mahwah, NJ: Erlbaum.

Besch, T. M., \& Lee, J. S. (2018). On toleration in social work. European Journal of Social Work, 21(2), 311-322.

Bisman, C. (2004). Social work values: The moral code of the profession. British Journal of Social Work, 34(1), 109-123.

Boddy, J., Agllias, K., \& Gray, M. (2012). Mentoring in social work: Key findings from a women's community-based mentoring program. Journal of Social Work Practice, 26(3), 385-405.

Boucher, H. C. (2011). The dialectical self-concept II: Cross-role and within-role consistency, wellbeing, self-certainty, and authenticity. Journal of Cross-Cultural Psychology, 42(7), 1251-1271.

Brown, M. E., \& Treviño, L. K. (2006). Ethical leadership: A review and future directions. Leadership Quarterly, 17(6), 595-616.

Casali, G. L. (2007). A quest for ethical decision making: Searching for the Holy Grail and finding the sacred trinity in ethical decision-making by managers. Social Responsibility Journal, 3(3), 50-59.

Casali, G. L. (2011). Developing a multidimensional scale for ethical decision making. Journal of Business Ethics, 104(4), 485-497.

Casali, G. L., \& Day, G. E. (2015). A taxonomic approach to understanding managerial ethical decision-making approaches of clinically and non-clinically trained healthcare managers in Australia. Asia Pacific Journal of Health Management, 10(3), SI8-SI17.

Clark, C. (2012). From rules to encounters: Ethical decision-making as a hermeneutic process. Journal of Social Work, 12(2), 115-135.

du Preez, E., \& Goedeke, S. (2013). Second order ethical decision-making in counselling psychology: Theory, practice and process. New Zealand Journal of Psychology, 42(3), 44-49.

Elpers, K., \& Westhuis, D. J. (2008). Organizational leadership and its impact on social workers' job satisfaction: A national study. Administration in Social Work, 32(3), 26-43.

Evans, T., \& Hardy, M. (2017). The ethics of practical reasoning - exploring the terrain. European Journal of Social Work, 20(6), 947-957.

Floyd, M. R., \& Rhodes, D. (2011). Unforeseen implications of regulation to authenticity in clinical practice. Clinical Social Work Journal, 39(3), 308-314.

Freeman, R. E., \& Auster, E. R. (2011). Values, authenticity, and responsible leadership. Journal of Business Ethics, 98(1), 15-23.

Freud, S., \& Krug, S. (2002). Beyond the code of ethics, part I: Complexities of ethical decision making in social work practice. Families in Society: The Journal of Contemporary Human Services, 83(5-6), 474-482.

Gellis, Z. D. (2001). Social work perceptions of transformational and transactional leadership in health care. Social Work Research, 25(1), 17-25. 
Gupta, A., Blumhardt, H., \& ATD Fourth World. (2018). Poverty, exclusion and child protection practice: The contribution of 'the politics of recognition\&respect'. European Journal of Social Work, 21(2), 247-259.

Hansen, J. T. (2012). Extending the humanistic vision: Toward a humanities foundation for the counseling profession. Journal of Humanistic Counseling, 51(2), 133-144.

Hedin, U. C., \& Månsson, S. A. (2012). Whistleblowing processes in Swedish public organisationscomplaints and consequences. European Journal of Social Work, 15(2), 151-167.

Hyslop, I. (2018). Neoliberalism and social work identity. European Journal of Social Work, 21(1), $20-31$.

Joseph, S. (2017). The real deal. Psychologist, 30(1), 34-37.

Jungers, C. M., \& Gregoire, J. (2016). Authenticity in ethical decision making: Reflections for professional counselors. Journal of Humanistic Counseling, 55(2), 99-110.

Kirkpartick, I., Ackroyd, S., \& Walker, R. (2005) The new managerialism and the public service professionals: Change in health, social services and housing. Basingstoke, England: Palgrave Macmillan.

Kjørstad, M. (2017). Do your duty—demand your right: A theoretical discussion of the norm of reciprocity in social work. European Journal of Social Work, 20(5), 630-639.

Knoll, M., Lord, R. G., Petersen, L. E., \& Weigelt, O. (2016). Examining the moral grey zone: The role of moral disengagement, authenticity, and situational strength in predicting unethical managerial behavior. Journal of Applied Social Psychology, 46(1), 65-78.

Lawler, J. (2007). Leadership in social work: A case of caveat emptor? British Journal of Social Work, $37(1), 123-141$.

Lee, Y., \& Kim, J. N. (2017). Authentic enterprise, organization-employee relationship, and employee-generated managerial assets. Journal of Communication Management, 21(3), 236-253.

Lenton, A. P., Slabu, L., \& Sedikides, C. (2016). State authenticity in everyday life. European Journal of Personality, 30(1), 64-82.

Liang, S. (2017). Linking leader authentic personality to employee voice behaviour: A multilevel mediation model of authentic leadership development. European Journal of Work and Organizational Psychology, 26(3), 434-443.

Maltby, J., Wood, A. M., Day, L., \& Pinto, D. (2012). The position of authenticity within extant models of personality. Personality and Individual Differences, 52(3), 269-273.

Mary, N. L. (2005). Transformational leadership in human service organizations. Administration in Social Work, 29(2), 105-118.

May, D. R., Chan, A. Y., Hodges, T. D., \& Avolio, B. J. (2003). Developing the moral component of authentic leadership. Organizational Dynamics, 32(3), 247-260.

Nelson, D. L., McEvoy, C. L., \& Schreiber, T. A. (2004). The University of South Florida free association, rhyme, and word fragment norms. Behavior Research Methods, Instruments, \& Computers, 36(3), 402-407.

Osmo, R., \& Landau, R. (2006). The role of ethical theories in decision making by social workers. Social Work Education, 25(8), 863-876.

Petkeviciute, N., Barvydiene, V., \& Surpikiene, N. (2018). Authentic leadership: Leader-follower relationship genesis. Transformations in Business \& Economics, 17(1), 83-99.

Proctor, E. K. (2002). Decision making in social work practice. Social Work Research, 26(1), 3-7.

Rogowski, S. (2011). Managers, managerialism and social work with children and families: The deformation of a profession? Practice, 23(3), 157-167. 
Schlegel, R. J., Vess, M., \& Arndt, J. (2012). To discover or to create: Metaphors and the true self. Journal of Personality, 80(4), 969-993.

Schwartz, M. S. (2016). Ethical decision-making theory: An integrated approach. Journal of Business Ethics, 139(4), 755-776.

Shamir, B., \& Eilam, G. (2005). ‘What's your story?' A life-stories approach to authentic leadership development. Leadership Quarterly, 16(3), 395-417.

Shapira-Lishchinsky, O. (2014). Simulations in nursing practice: Toward authentic leadership. Journal of Nursing Management, 22(1), 60-69.

Smith, E. E., \& Medin, D. L. (1981). Categories and concepts. Cambridge, MA: Harvard University Press.

Staub-Bernasconi, S. (2017). The problem with 'social problems' as domain of social work: A critical approach to the Melbourne 'global definition of social work' of 2014 and constructivist theories of social problems. European Journal of Social Work, 20(6), 958-971.

Tafvelin, S., Hyvönen, U., \& Westerberg, K. (2014). Transformational leadership in the social work context: The importance of leader continuity and co-worker support. The British Journal of Social Work, 44(4), 886-904.

Trowler, I. (2017). Turning the ship around: Reflections on changing a nation's social work practice system in the interests of children and families. Journal of Children's Services, 12(2-3), 197-201.

Ulrich, C. M., Taylor, C., Soeken, K., O’Donnell, P., Farrar, A., Danis, M., \& Grady, C. (2010). Everyday ethics: Ethical issues and stress in nursing practice. Journal of Advanced Nursing, 66(11), 2510-2519.

Urek, M. (2017). Unheard voices: Researching participation in social work. European Journal of Social Work, 20(6), 823-833.

Wood, A. M., Linley, P. A., Maltby, J., Baliousis, M., \& Joseph, S. (2008). The authentic personality: A theoretical and empirical conceptualization and the development of the Authenticity Scale. Journal of Counseling Psychology, 55, 385-399.

Yeung, K. S. S., Ho, A. P. Y., Lo, M. C. H., \& Chan, E. A. (2009). Social work ethical decision making in an inter-disciplinary context. British Journal of Social Work, 40(5), 1573-1590.

Zhu, W., May, D. R., \& Avolio, B. J. (2004). The impact of ethical leadership behavior on employee outcomes: The roles of psychological empowerment and authenticity. Journal of Leadership \& Organizational Studies, 11(1), 16-26.

\section{Tables and Figures}

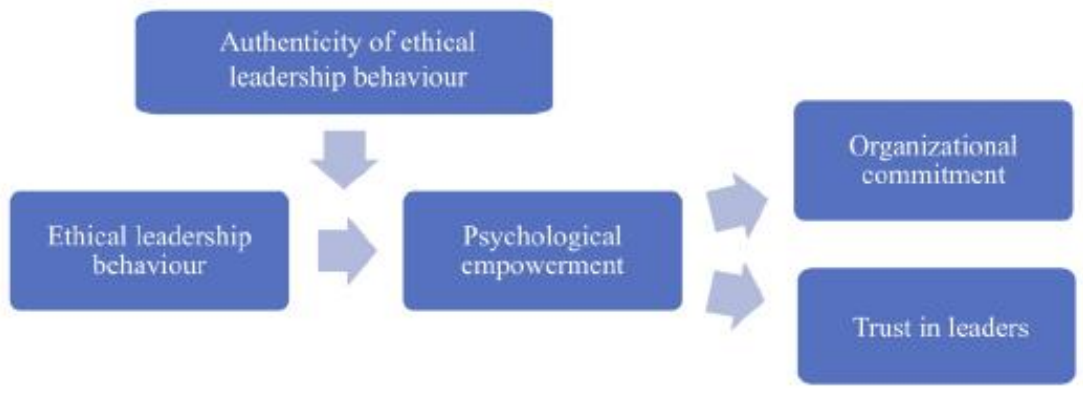

Figure 1. Model of authentic ethical leadership behaviour (adapted from Zhu et al., 2004). 


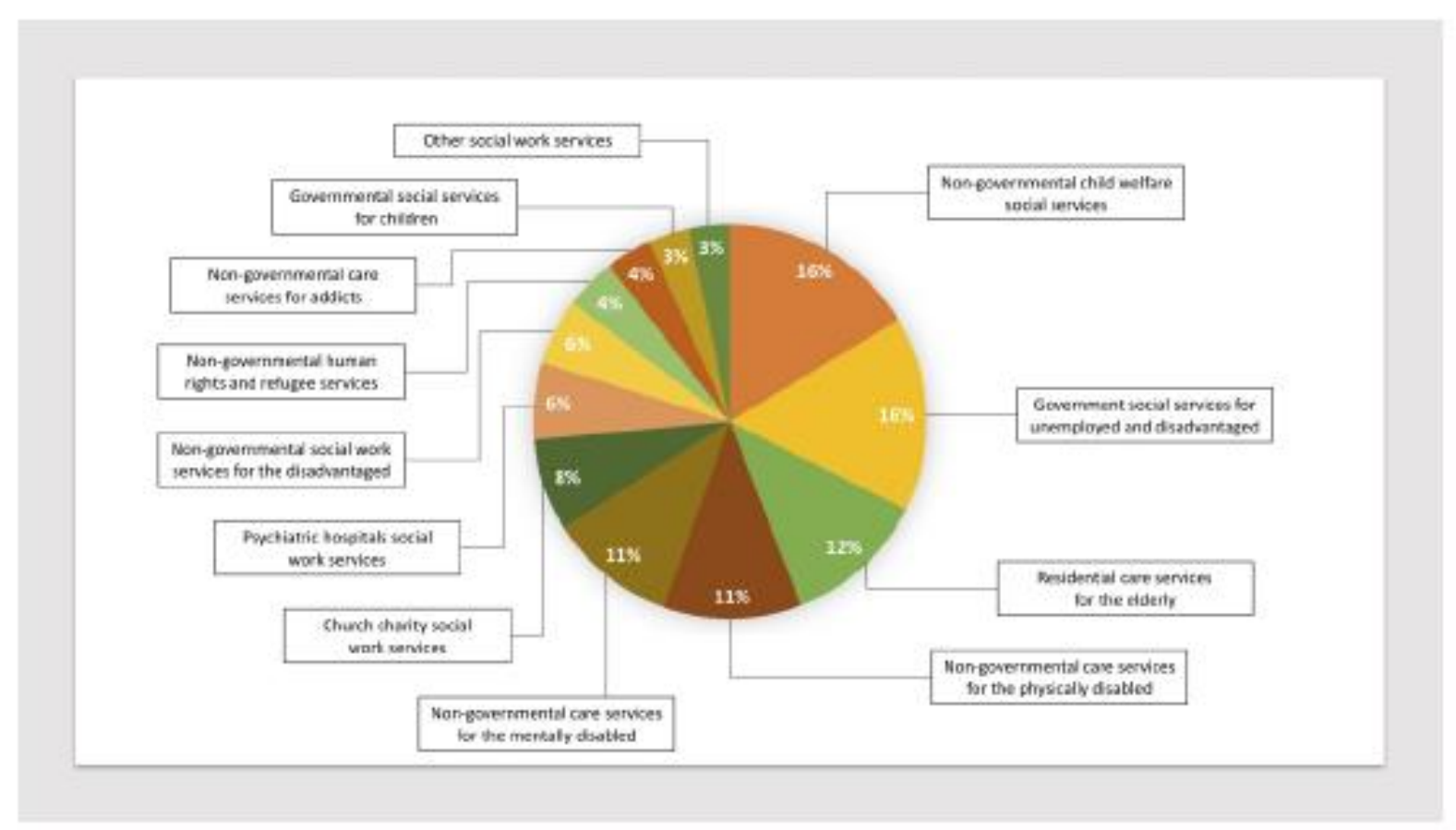

Figure 2. Proportions of social work organization types in the sample.

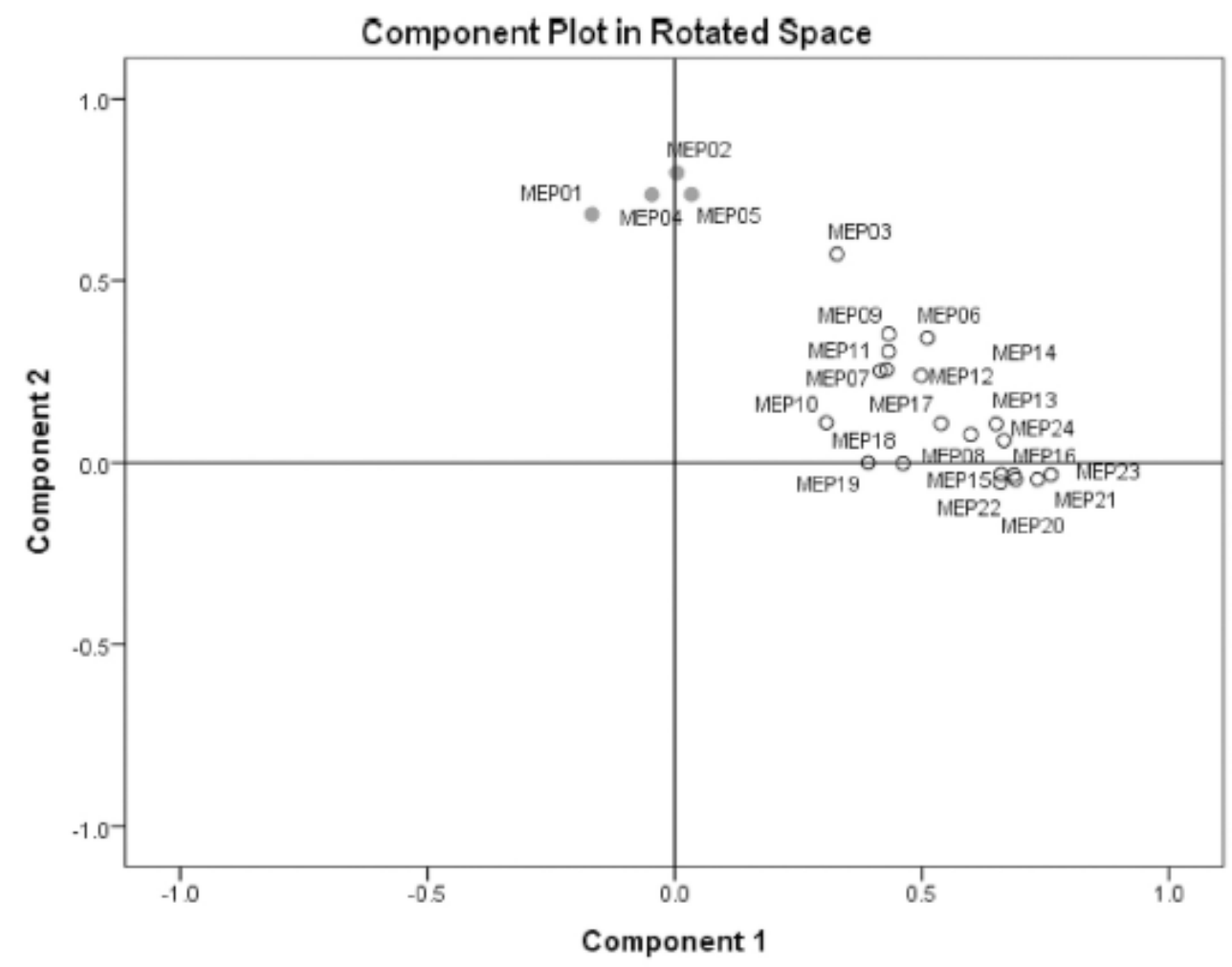

Figure 3. Principal Component Analyses of the MEP scale. 


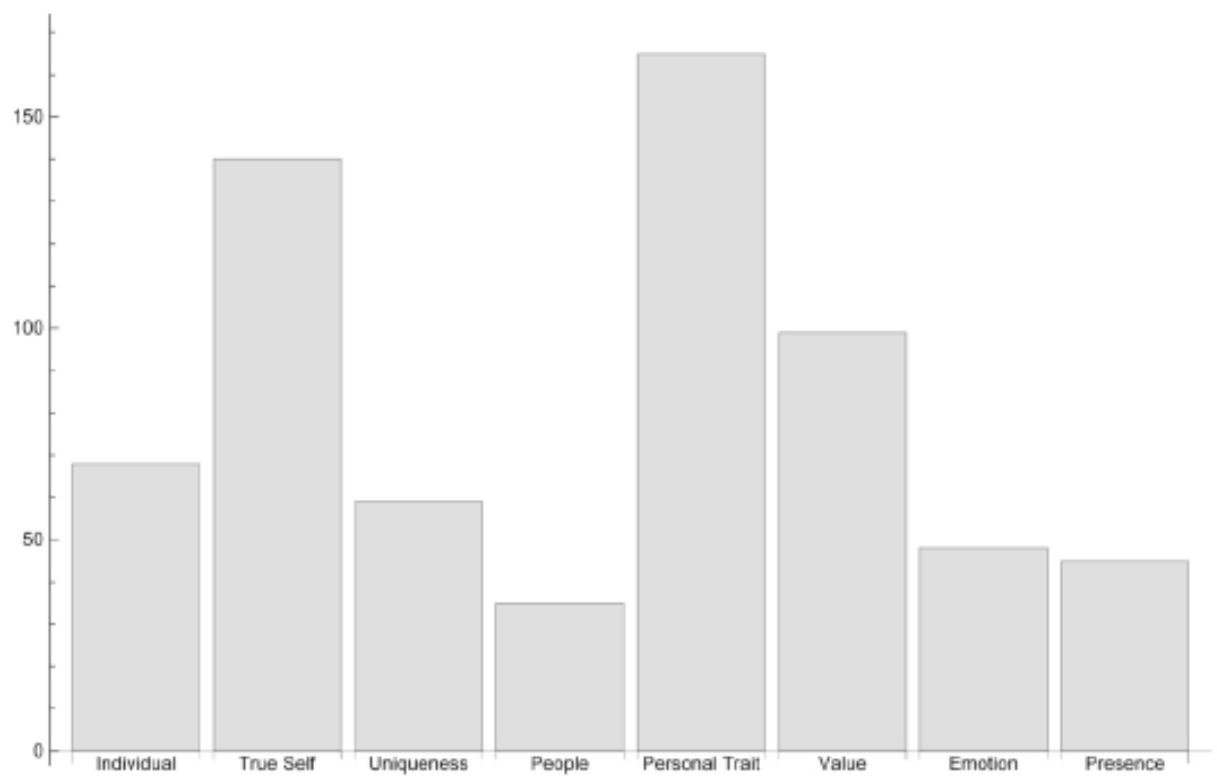

Figure 4. Occurrences of authenticity-related associations. The numbers of participants that reported at least one association pertaining to particular category are included.

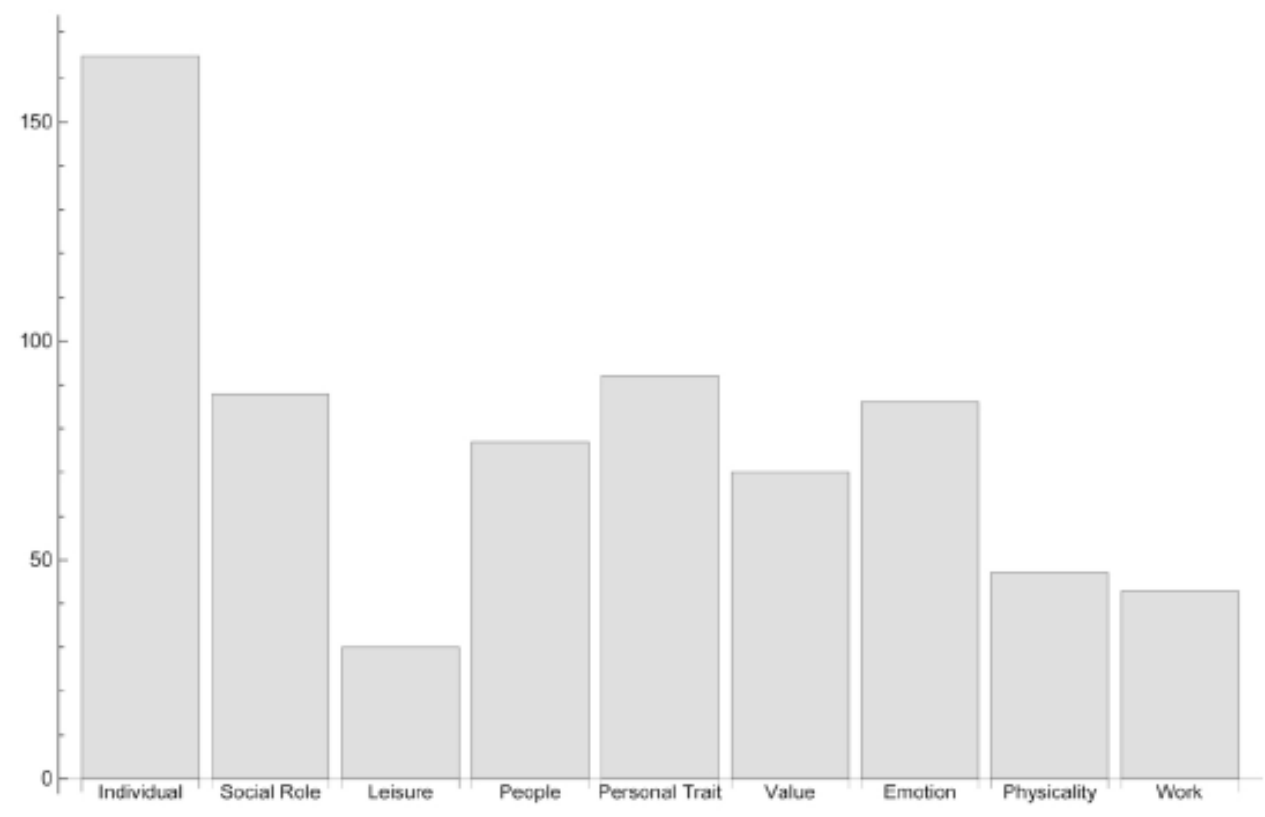

Figure 5. Occurrences of self-related associations. The numbers of participants that reported at least one association pertaining to particular category are included. 

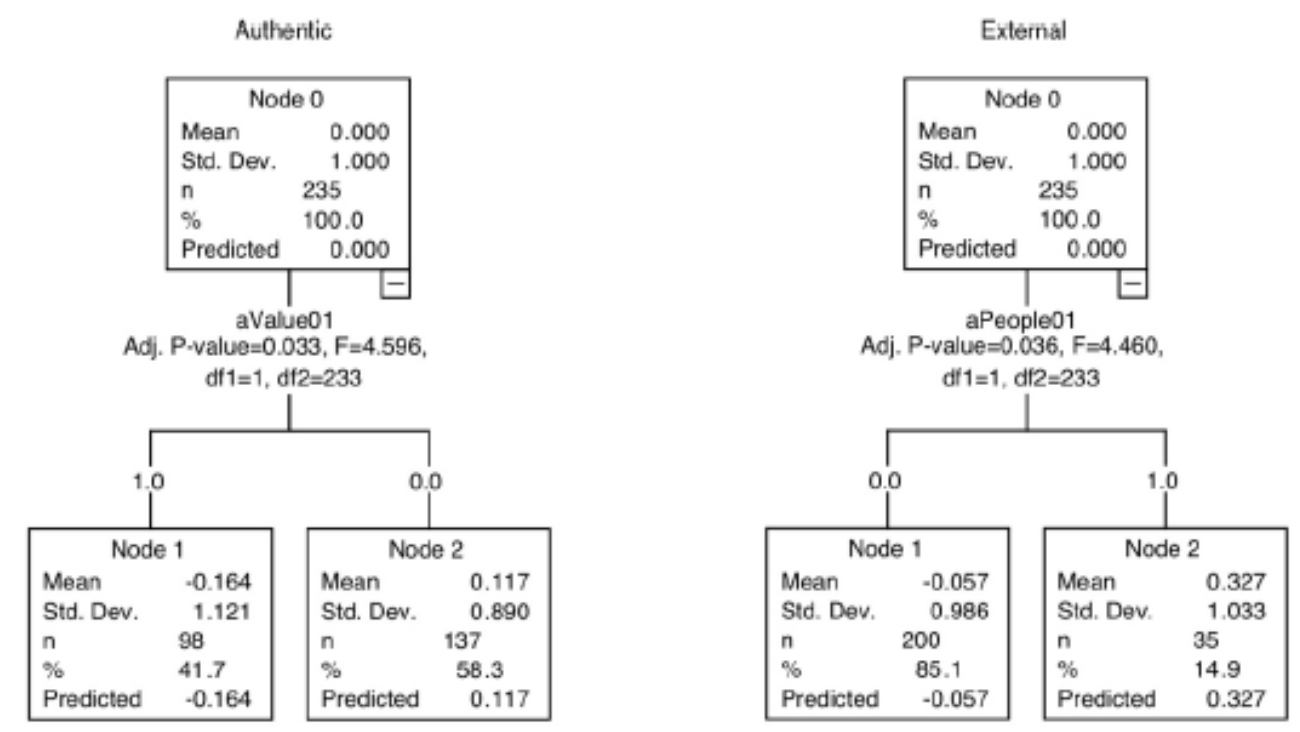

Figure 6. Decision trees showing the relationships between authenticity measured by the AS and authenticity-related associations.
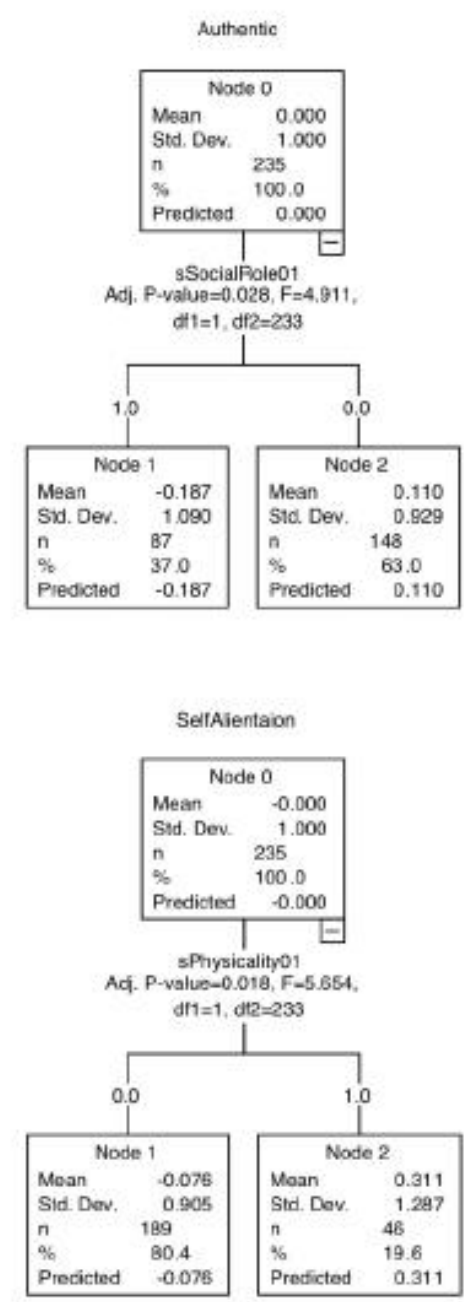

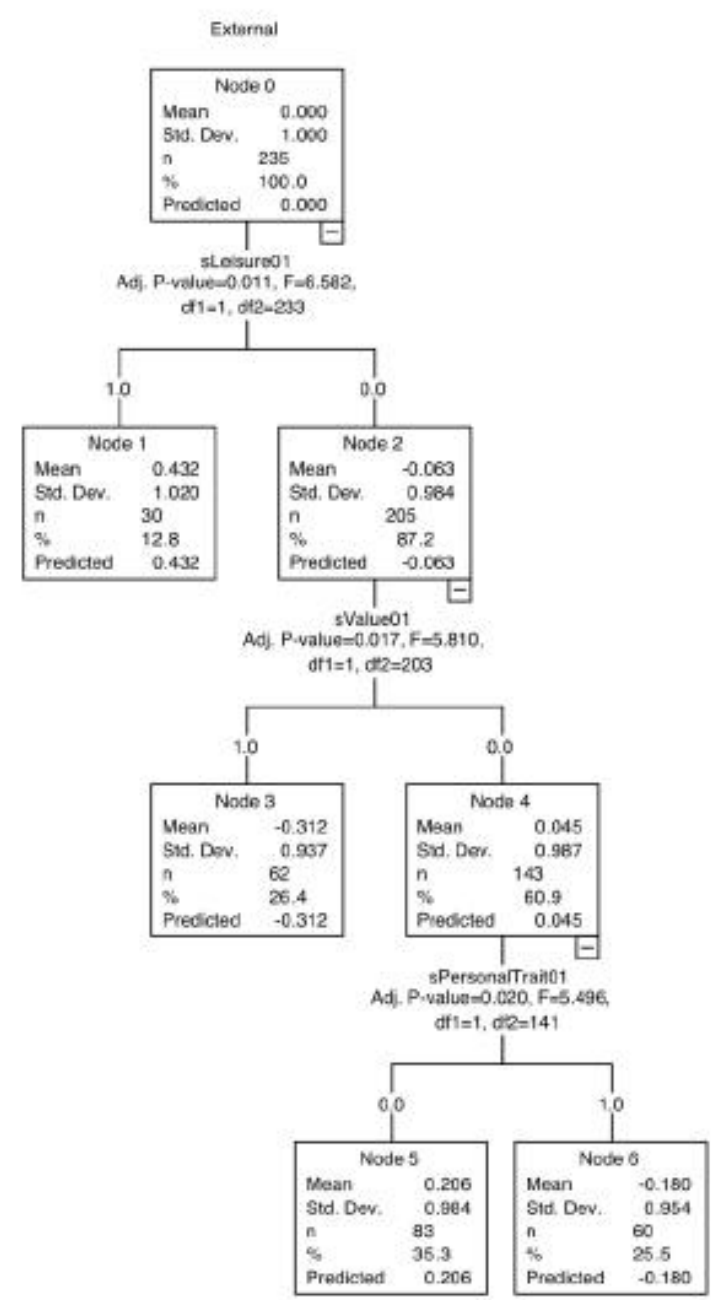

Figure 7. Decision trees showing the relationships between authenticity measured by the AS and self-related associations. 